\title{
A Diabatic Circulation Experiment in a Two-Dimensional Photochemical Model
}

\author{
P. D. Guthrie, C. H. Jackman, J. R. Herman, and C. J. McQuillan
}

NASA Goddard Space Flight Center, Atmospheric Chemistry Branch

\begin{abstract}
A two-dimensional photochemical model based on diabatic circulation has been used to simulate the behavior of $\mathrm{N}_{2} \mathrm{O}, \mathrm{CFCl}_{3}(\mathrm{~F}-11)$, and $\mathrm{CF}_{2} \mathrm{Cl}_{2}(\mathrm{~F}-12)$. The circulation is based on estimates of net heating from the ground to $60 \mathrm{~km}$. Eddy diffusion has been reduced with respect to other model studies with $K_{\mathrm{zz}}=2 \times 10^{3} \mathrm{~cm}^{2} \mathrm{~s}^{-1}$ everywhere above 100 mbar. Resulting tracer profiles show reasonable agreement with measured profiles in the tropics and fall off much more sharply with altitude than those produced by models using larger values of $K_{z z}$. The agreement obtained is at least as good as that obtained with adjustable, eddy diffusion parameters. The diabatic circulation treatment is more closely related to real physical processes and thus more easily interpreted. Diffusive mixing appears to be more important in determining the details of the tracer distributions than the basic morphology.
\end{abstract}

\section{INTRODUCTION}

Photochemical models have evolved, over the last 10 years or so, into one of the primary classes of tools used in studying the chemical behavior of the atmosphere. These models now range from box chemistry models to three-dimensional versions with coupled treatments of radiation, dynamics, and chemistry, and there will always be some problems that require even more sophisticated models than available computer resources can support. One of the first steps in any attempt to model atmospheric phenomena must be the selection of a modeling tool at an appropriate level of physical approximation. It is the purpose of this paper to investigate the ability of a two-dimensional (zonally averaged) model, using transport based on a diabatically driven circulation without substantial eddy diffusion, to provide a good simulation of atmospheric behavior as measured by upward flowing long-lived tracer distributions.

The diversity of atmospheric phenomena has led to the development of a hierarchy (in dimensionality) of models. At one extreme there are simple box models, useful for studying problems involving rapid, complex chemistry where transport is unimportant. At the other extreme is the three-dimensional interactive model, which attempts to encompass most of the underlying physical processes of the atmosphere, including limited chemistry. Such models are primarily useful in studying problems of complex atmospheric motion and energy flows. In the middle lie the one-dimensional and twodimensional models. The former is often thought of as representing global average altitude profiles of chemical species, while the latter is most useful for problems involving latitudinal distributions and seasonal variations of species of interest. The two-dimensional models are particularly suited to studies of photochemical phenomena where the transport of source and reservoir species is important, but the model time required produces a prohibitive computational load if one uses a 3-D model. For example, in a 2-D model one can perform several multiyear simulations to test sensitivities to variations : of ground sources within a reasonable amount of computer time. Such models can also be used to provide realistic initial distributions for 3-D models, as for the initial $\mathrm{NO}_{x}$ distribution for the 3-D ozone studies of Cunnold et al. [1975]. However, this procedure depends on the degree to which the 2-D transport represents a zonal average consistent with the

This paper is not subject to U.S. copyright. Published in 1984 by the American Geophysical Union.

Paper number 4D0715.
3-D model. If the 2-D model is based on highly parameterized eddy coefficients from atmospheric measurements, this consistency is difficult to achieve. Finally, the 2-D models provide an interpretive bridge between the relative simplicity of a 1-D model profile and the inherently more complex and variable 3-D simulations.

There remain conceptual difficulties in interpeting 2-D transport [see, for example, Danielson, 1981], and one must be wary not to attempt to push the model beyond the inherent limits of the basic zonally averaged formulation. For example, it seems unlikely that a 2-D model could properly simulate transport during a stratospheric warming event, although the net effect can be parameterized [Schoeberl and Strobel, 1980]. The time scale for a zonally averged model is ultimately fixed by the time scale for zonal mixing (that is, for the atmosphere to "average" a perturbation around a latitude circle), which is of the order of several weeks. During the recent El Chichon eruption, it took 3 weeks for the leading edge of the aerosol cloud to wrap around and merge with the trailing edge [Krueger, 1983; Robock and Matson, 1983]. In testing the limits of a model based on a particular transport treatment, simulations of tracer distributions allow us to focus on the long-term net transport effects. Subsequent studies will focus on the adequacy of this transport treatment in simulating seasonal cycles of ozone and other photochemically active species.

Many existing 2-D models, including that used in this study, can be described as specified transport models; that is, a change in species distributions (e.g., ozone) does not produce a self-consistent change in the atmospheric circulation. For the present study we have chosen to specify the 2-D transport fields at monthly intervals and to neglect feedback processes caused by changes in the distributions of radiatively active species. A number of attempts have been made to include such a coupling [e.g., Garcia and Solomon, 1983; Harwood and Pyle, 1975; Vupputuri, 1978], but the problem of incorporating the details of transport feedbacks in a two-dimensional approximation, especially when the eddy contributions become large in comparison to the mean circulation, has not been completely resolved.

Although the goal of most photochemical modeling efforts is to simulate the behavior of a large number of interacting chemical species, the resulting complexity makes it quite difficult to disentangle the effects of the various approximations and parameterizations employed. For example, if the seasonal variations in profiles of species such as those in the $\mathrm{NO}_{x}$ and $\mathrm{HO}_{x}$ families are not properly simulted, is this to be attributed to an inaccurate treatment of transport or to an insufficient 

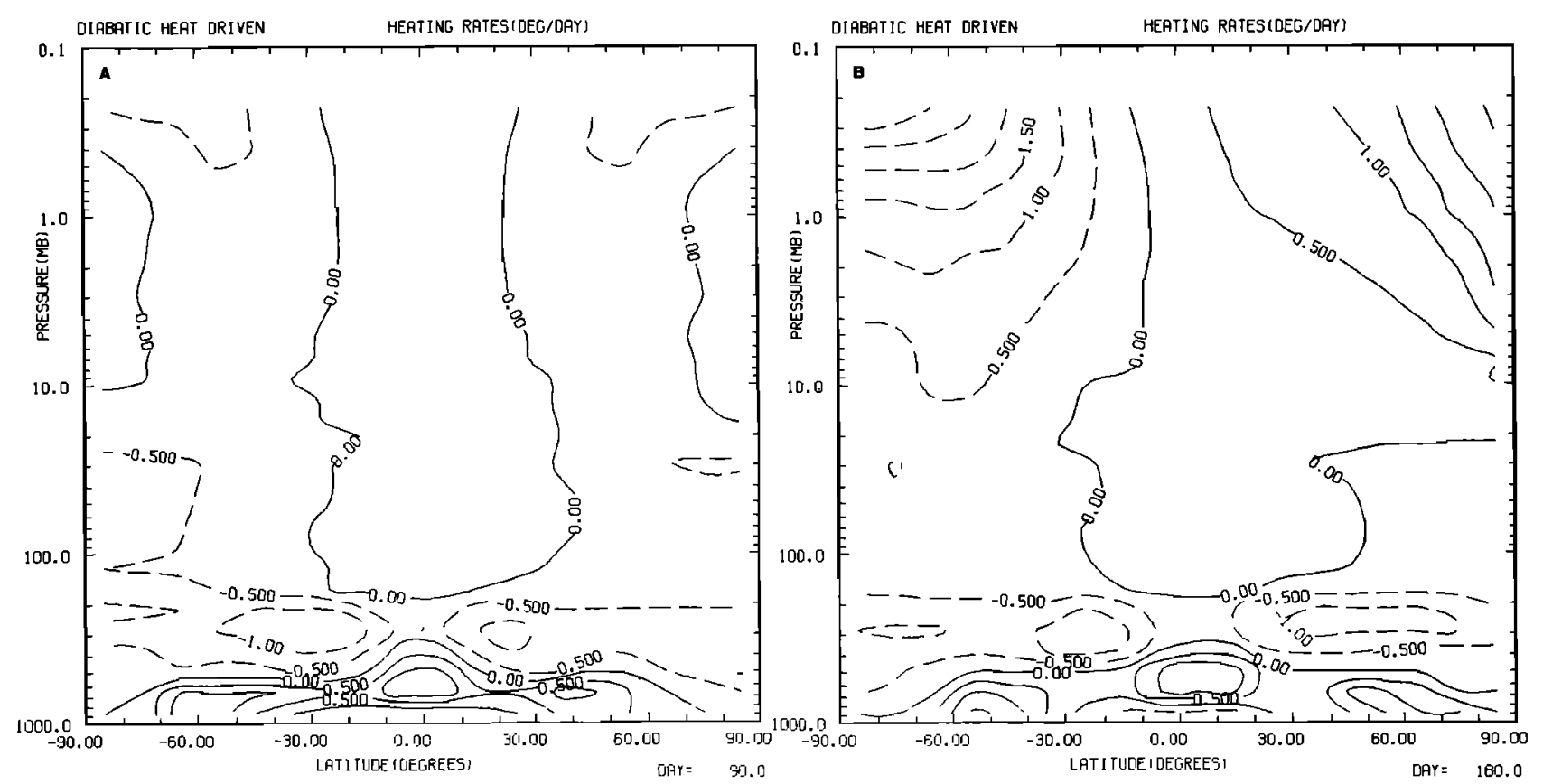

Fig. 1. Diabatic heating rates used for northern hemisphere: $(a)$ vernal equinox, (b) summer solstice.

reproduction of the annual ozone cycle as a result of a limited chemical treatment? Our strategy is to decouple these effects for the purposes of assessing the model approximations before attermpting to modify those approximations in order to do a full photochemical simulation. In order to study a specific transport parameterization we have specified ozone on the basis of an observed (over 1 year) distribution from Nimbus 7 data [McPeters et al., 1984], updated monthly. The $\mathrm{O}_{2}$ mixing ratio does not vary, but the column density above a given point changes as the model atmosphere responds to seasonal variations in temperature. Thus the calculated local ultraviolet flux should be a good approximation to that of the real atmosphere.

The first step is to consider three precursor or source gases: $\mathrm{N}_{2} \mathrm{O}, \mathrm{F}-11$, and $\mathrm{F}-12$. All three have sources at the ground and sinks primarily through stratospheric photolysis. Thus we are using an experimental circulation to transport photochemically sensitive traces through a reasonably realistic radiation field. The degree to which the model simulates the actual atmospheric behavior of those tracers is then a test of the ability of the circulation parameterization to simulate actual atmospheric transport. A demonstrated ability to do so is a necessary condition for using this circulation in more complex photochemical simulations.

\section{THE MODEL}

The model domain is from $-85^{\circ}$ to $+85^{\circ}$ in latitude at $10^{\circ}$ intervals and from the ground to approximately $60 \mathrm{~km}$ in altitude, with vertical resolution of about $2 \mathrm{~km}$ as represented by 30 levels in log pressure coordinates. At each point in the grid the model solves a set of $N$ species continuity equations of the form

$$
\frac{\partial S_{n}}{\partial t}=-\nabla \cdot F_{n}+P_{n}-L_{n} S_{n}
$$

where $S_{n}$ is the concentration of species $n, F_{n}$ is the flux of species $n, P_{n}$ is the volume production rate, and $L_{n}$ is the photochemical loss rate. The numerical technique used is
Newton-Raphson iteration with explicit forward time differencing at each point and alternating direction of integration in both coordinates (the "angled" derivative scheme of Roberts and Weiss [1966]). The spatial finite differences are centered fourth order in the interior and one-sided fourth order at the boundaries. (See the Appendix A for further discussion of numerical technique.) The boundary condition on the transport fields is zero transverse velocity at each boundary. Species boundary conditions may be specified as constant mixing ratio, specified flux (which may be time and latitude dependent), or specified deposition velocity. Although any combination of advective and eddy-diffusive transport parameters can be formally accommodated, the model is optimized for primarily advective transport; this is discussed further below under "Transport."

\section{Chemistry}

The chemical production and loss terms in equation (1) represent sums over many individual chemical processes. They are of the form

$$
\begin{aligned}
& P_{n}=\sum_{i} S_{i} J_{n i}+\sum_{i j} K_{n i j} S_{i} S_{j}+\sum_{i j k} K_{n i j k} S_{i} S_{j} S_{k} \\
& L_{n}=\sum_{i} J_{n i}+\sum_{j} K_{n j} S_{j}+\sum_{j k} K_{n j k} S_{j} S_{k}
\end{aligned}
$$

where the $J$ 's are photolysis rates and the $K$ 's are the two or three body reaction rates for the various relevant reactions. The $i, j, k$ subscripts represent individual photolysis pathways, binary reactions, and tertiary reactions, respectively, which contribute to the total production and loss rates for species $n$. Tables of these rates are given in the World Meteorological Organization [1981, hereafter referred to as WMO 81] report along with the cross sections for the computation of the $J$ coefficients for photolysis. Appendix B presents the reactions used in this study. In this model, scattering is neglected so that a simple Beer's law calculation of the solar flux within the atmosphere can be used. The effects of spherical geometry in the earth's atmosphere are approximated by use of the Chapman function [McCartney, 1976]. The solar flux above 



Fig. 2. Vertical and meridional winds for $(a),(b)$, vernal equinox and $(c),(d)$ summer solstice. Shading shows descending motion.

the atmosphere is taken from Mount and Rottman [1981] for wavelengths shorter than $165 \mathrm{~nm}$. Between 165 and $400 \mathrm{~nm}$ the flux used is given by D. F. Heath (private communication, 1981, see also WMO 81), and for wavelengths longer than 400 $\mathrm{nm}$ the flux is taken from WMO 81 . Where the flux data sets are joined the values of Heath are used as the reference values for smoothly joining the data.

The procedure for assembling the terms entering into $P_{n}$ and $L_{n}$ is similar to that described by Herman [1979]. Each reaction rate and $J$ coefficient is diurnally averaged. The diurnally averaged $J$ coefficients are obtained by averaging the instantaneous $J$ values over 24 hours for each latitude contained in the grid and for several values of the solar declination angle. Linear interpolation is used for the diurnal averages for other solar declinations. The diurnal averages of the chemical reaction terms are formed by integrating a onedimensional version of the chemistry equations and forming the 24-hour average of each reaction at each altitude at $30^{\circ} \mathrm{N}$ latitude for spring equinox. The largest error arising from the use of this single set of diurnal average reaction rates occurs in the polar regions in the months just before and after winter night. For the tracers considered here the dominant processes are photolytic, and the accuracy is essentially independent of latitude. We approximate the solar spectrum with 39 wavelength intervals.

Recently, Herman and Mentall [1982] have suggested that absorption cross sections for $\mathrm{O}_{2}$ between 200 and $230 \mathrm{~nm}$ should be smaller than those measured by Hasson and $\mathrm{Ni}$ cholls [1971]. Several authors [Froidevaux and Yung, 1982; Brasseur et al., 1983] have compared the results of the two sets 


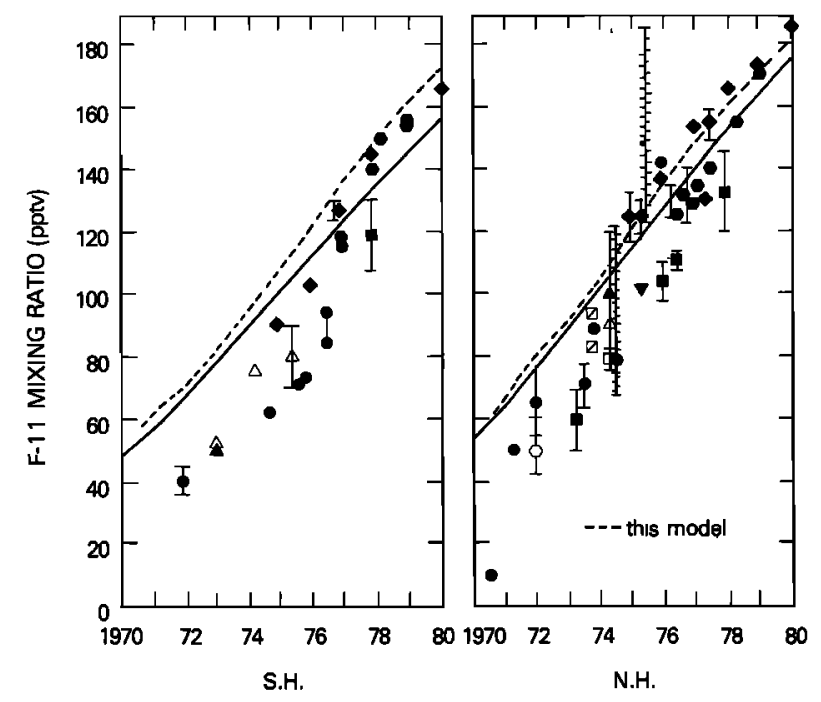

Fig. 3. Time history of F-11 (after WMO 81). The points are tropospheric measurements, the solid line is the 1-D model result of Logan et al. [1981], and the dashed line is the result of this model lor $45^{\circ} \mathrm{N}$ and $45^{\circ} \mathrm{S}$ at $\sim 500$ mbar. See WMO 81 for data references.

of cross sections in 1-D models and found substantial differences. Below $200 \mathrm{~nm}$, we have used $\mathrm{O}_{2}$ cross sections based on Allen and Frederick [1982]; between 200 and $230 \mathrm{~nm}$, Herman and Mentall [1982]; and above $230 \mathrm{~nm}$, Hasson and Nicholls [1971].

The model is run in a time-dependent mode with a time step of three days. The declination and fraction of day and night [after $R$ undel, 1977] are changed every time step.

\section{TRANSPORT}

The transport term in (1) must be expressed in terms of some set of parameters that are determined by the physical processes of interest. Clearly, a model of this type cannot include exact treatment of sub-grid-scale physics, nor can it include the physics of the planetary wave phenomena noted in the real atmosphere. In practice the parameterization usually comes down to only two types of processes: advection by winds, which preserves air parcel properties, and eddy diffusion, which represents atmospheric motions that mix air parcels and thus relax concentration gradients.

The first generation of specified-transport, 2-D photochemical models [Widhopf, 1975; Crutzen, 1975; Whitten et al., 1977] was based on the use of locally measured (i.e., Eulerian) winds and the eddy diffusion treatment of Reed and German [1965]. The components of the eddy diffusion tensor must then be obtained through some inversion procedure based on tracer measurements in the real atmosphere. This approach produces mean and eddy motions that are nearly cancelling, not necessarily self-consistent [Mahlman, 1975], and whose net effect is the small residual of two nearly equal but opposite fluxes, neither of which is well determined by measurements. Attempts to improve the situations are reviewed in chapter 2 of WMO 81.

One suggested alternative is to base the model on the "residual mean" circulation as outlined by Pyle and Rogers [1980] and Holton [1981] and in particular to identify that circulation with that driven by diabatic heating [Dunkerton, 1978]. A question remains as to the adequacy of the approximation that, in such a model, diffusive transport will be small in comparison to advective transport and may be neglected or, at most, considered as a "correction" to the basic advective circulation. Since the approximation must break down at some spatial or temporal scale of atmospheric behavior, it is important to determine where, if anywhere, the approximation is good, as evidenced by its ability or inability to simulate observed atmospheric tracer distributions.

The great advantage of the residual mean approach is that transport processes divide neatly into advection (including that resulting from eddy transport if one goes beyond the diabatic approximation) and diffusive mixing, as represented by the symmetric portion of the eddy diffusion tensor. The flux divergence may be written [see, for example, Holton, 1981] as

$$
\begin{aligned}
\nabla \cdot F=\frac{1}{R_{E} \cos \phi} \frac{\partial}{\partial \phi}(X \rho v \cos \phi)+\frac{\partial P}{\partial Z} & \frac{\partial}{\partial P}(\rho X w) \\
& +\nabla \cdot[\rho \hat{K} \cdot \nabla X]
\end{aligned}
$$

or after expanding, rearranging, and neglecting the offdiagonal terms in the eddy diffusion tensor:

$$
\begin{aligned}
\nabla \cdot F= & \frac{\partial^{2} X}{\partial P^{2}} \cdot\left[-q^{2} \rho K_{z z}\right] \\
& +\frac{\partial X}{\partial P} \cdot\left[q \rho w-q \frac{\partial}{\partial P}\left(q \rho K_{z z}\right)-\frac{2 q \rho K_{z z}}{R_{E}}\right] \\
& +\frac{\partial^{2} X}{\partial \phi^{2}} \cdot\left[-\frac{\rho K_{y y}}{R_{E}^{2}}\right]+\frac{\partial X}{\partial \phi} \\
& \cdot\left[\frac{\rho v}{R_{E}}-\frac{1}{R_{E}^{2}} \frac{\partial}{\partial \phi}\left(\rho K_{y y}\right)+\frac{\tan \phi}{R_{E}^{2}} \rho K_{y y}\right] \\
& +X \cdot\left[q \frac{\partial}{\partial P}(\rho w)+2 \frac{\rho w}{R_{E}}+\frac{1}{R_{E} \cos \phi} \frac{\partial}{\partial \phi}(\rho v \cos \phi)\right]
\end{aligned}
$$

where $X$ is mixing ratio, $\rho$ is atmospheric number density $\left(\mathrm{m}^{-3}\right), P$ is $\ln$ (pressure/1013 mbar), $\phi$ is latitude, $q$ is $\partial P / \partial Z$ and $Z$ is altitude $\left(\mathrm{m}^{-1}\right.$ and $\mathrm{m}$ ), $R_{E}$ is the radius of the earth $(\mathrm{m}), w$ is vertical velocity $\left(\mathrm{m}-\mathrm{s}^{-1}\right), v$ is meridional (northward)

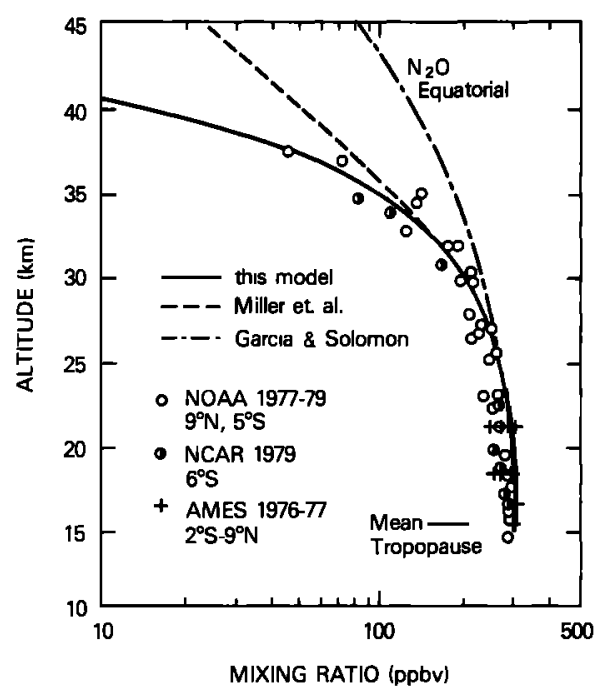

Fig. 4. Computed equatorial $\mathrm{N}_{2} \mathrm{O}$ profiles and measurements. In Figures 4 through 9 the data points are taken from WMO 81, which see for references. 
velocity $\left(\mathrm{m}-\mathrm{s}^{-1}\right)$,

$$
\tilde{K} \simeq\left|\begin{array}{cc}
K_{y y} & 0 \\
0 & K_{z z}
\end{array}\right|
$$

is the eddy diffusion tensor, and $K_{y y}, K_{z z}$ are eddy diffusion coefficients $\left(\mathrm{m}^{2}-\mathrm{s}^{-1}\right)$. Note that the wind velocities and diffusion coefficients are in standard spatial coordinates (rather than latitude-ln $P$ ) in order to facilitate comparison with other work.

\section{THE MODEL EXPERIMENT}

The basic procedure of this model experiment is to simulate trace gas profiles by using the diabatic circulation in a realistic photolysis environment. Our intent is to evaluate the contention that the diabatic circulation provides a "good" first approximation of transport in a 2-D model [Holton and Wehrbein, 1980] without substantial eddy diffusion. The required data for this experiment are total diabatic heating rates and temperatures throughout the model domain at monthly intervals. Although one could use the zonally averaged output of a GCM, for our purpose we would prefer heating rates based primarily on atmospheric measurements rather than on a particular model computation. No such self-consistent data base exists, but reasonable approximations can be constructed. Solstice and equinox heating rates above $20 \mathrm{~km}$ are available from Murgatroyd and Singleton [1961], and seasonal average heating rates from $30 \mathrm{~km}$ to the ground are available in Newell et al. [1974]. The low-altitude values contain latent heat release as well as radiative effects. The net radiative heating used by Newell et al. was that of Dopplick [1974]. We have corrected the radiative contribution in accordance with Dopplick [1979] wherever the correction was greater than $1 \%$. Unfortunately, the different sets of data do not match in the region of overlap. An approach taken by Miller et al. [1981] is to scale the Murgatroyd and Singleton rates uniformly by a factor of 0.4. Although adopting this procedure leaves large mismatches in various places at various seasons, it is probably as good as any other arbitrary modification and allows comparison with the Miller et al. model results. The resultant heating rates are shown in Figure 1 for northern hemisphere vernal equinox and summer solstice. Seasonal temperatures have been taken from Murgatroyd [1969]. The grid was filled out for four seasons by using spatial interpolation, and the intervening months filled in by using point-by-point temporal interpolation. As noted above, this version of the diabatic circulation is not definitive. One could merge the heating rates in other ways, perhaps adjusting the values below the merge level instead of, or in addition to, adjusting them above that

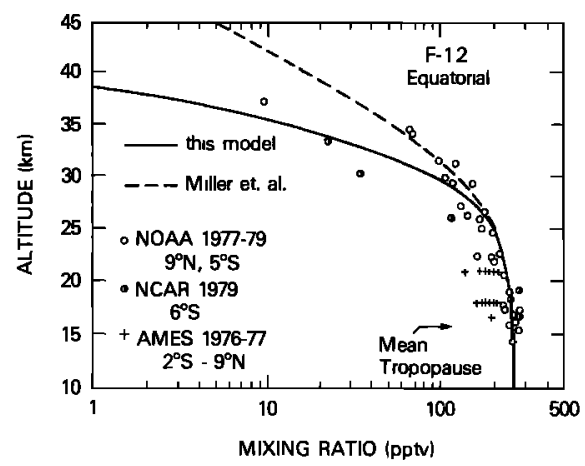

Fig. 5. Computed equatorial F-12 profiles and measurements.

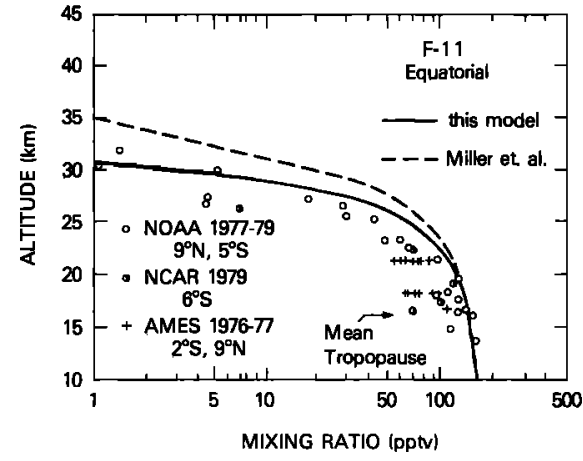

Fig. 6. Computed equatorial F-11 profiles and measurements.

level. However, the lower level heating rates are the more recent and are based on a more detailed treatment than are those of Murgatroyd and Singleton. More importantly, using the specified rates in the troposphere and lower stratosphere produces good agreement with tropical mixing ratio profiles of all three tracers considered here. These profiles depend on the strength of the upward drive in the tropical lower stratosphere. Adjusting these heating rates upward, rather than those in the upper stratosphere downward, will displace the tropical profiles upward with respect to the measurements.

The characteristic features of the diabatic circulation are (1) rising motion in the tropics and descending motion at high latitudes in the lower stratosphere and troposphere, and (2) the single pole-to-pole cell in the upper stratosphere at solstice. The altitude of transition from two cells to one and the latitude of transition from rising motion to descending motion are uncertain and depend on the details of the heating rate distributions.

The heating rates are converted to wind fields through the relation derived by Dunkerton [1978]:

$$
w=\frac{Q}{\Gamma-\Gamma_{A}}
$$

where $w$ is vertical wind $\left(\mathrm{m} \mathrm{s}^{-1}\right), Q$ is the heating $\left(\mathrm{K}-\mathrm{s}^{-1}\right), \Gamma$ is the temperature lapse rate $\left(K-\mathrm{m}^{-1}\right)$, and $\Gamma_{A}$ is the adiabatic lapse rate $\left(\mathrm{K}-\mathrm{m}^{-1}\right)$. The meridional wind $v$ is obtained by integrating the mass continuity equation from pole to pole with $v=0$ at the boundaries, i.e.,

$$
\begin{aligned}
v(\phi, P)=-\frac{1}{\rho(\phi, P) \cos \phi} \int_{-90^{\circ}}^{\phi} R_{E} \cos \phi^{\prime} \\
\\
\cdot \frac{\partial P}{\partial Z} \frac{\partial\left[\rho\left(\phi^{\prime}, P\right) w\left(\phi^{\prime}, P\right)\right]}{\partial P} d \phi^{\prime}
\end{aligned}
$$

In order to conserve mass within the model and satisfy continuity the $w$ field was adjusted to yield zero net mass flux through each pressure level. The resulting wind fields rigorously conserve mass at each point in the grid for our finite differencing scheme. The vertical and meridional velocity fields for solstice and equinox are shown in Figure 2. Comparison with other results [e.g., Dunkerton, 1978; Garcia and Solomon, 1983] shows the same general pattern, except at the top of the model. The strong meridional jet as solstice appears much lower ( $\sim 55$ vs. $75 \mathrm{~km})$ because of the "cap" at $\sim 60 \mathrm{~km}$, with a zero-vertical-velocity boundary condition. In effect the meridional jet has been displaced downward by the selection of model domain. For present purposes this has no effect on our results, since the tracer mixing ratios become essentially inde- 

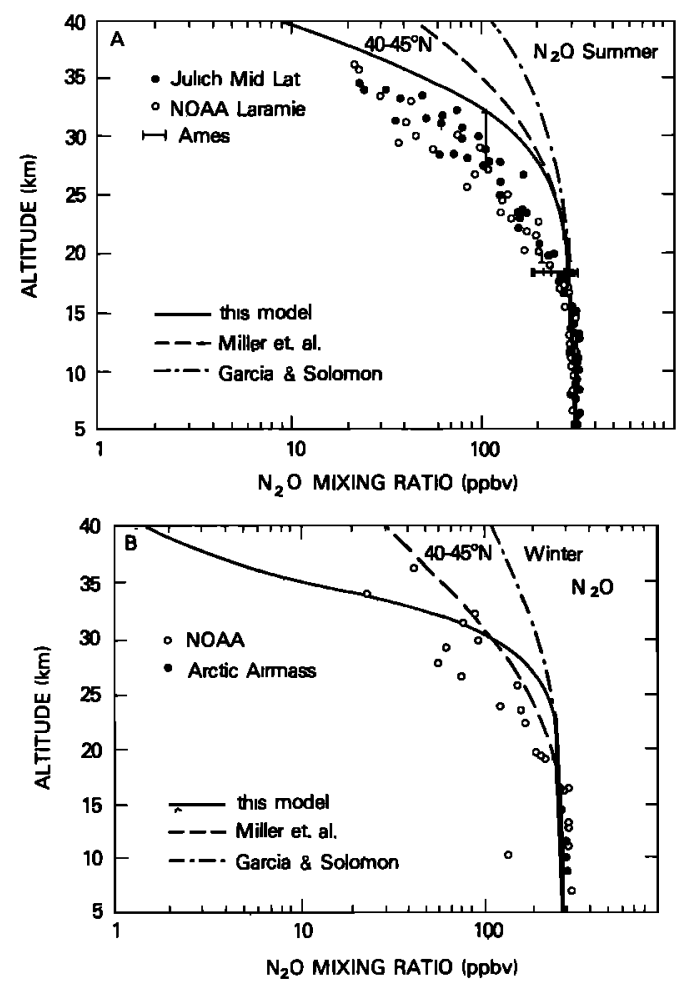

Fig. 7. Computed mid-latitude $\mathrm{N}_{2} \mathrm{O}$ profiles vs. measurements for (a) summer, (b) winter.

tectable at altitudes below the jet. For problems involving photochemically active species with sources in the upper stratosphere or mesosphere the treatment of the upper boundary would need to be reconsidered.

A primary goal of an advective transport model is to determine the degree to which the observed distribution of tracers can be explained by advective processes. Accordingly, we have attempted to minimize the dependence on eddy-diffusive transport. In this experiment the symmetric parts of the $K$ tensor, $K_{y y}$ and $K_{z z}$, are set to $2 \times 10^{9} \mathrm{~cm}^{2} \mathrm{~s}^{-1}$ and $2 \times 10^{3}$ $\mathrm{cm}^{2} \mathrm{~s}^{-1}$, respectively, everywhere above $100 \mathrm{mbar}$. There is no latitudinal variation, and $K_{y z}=K_{z y}=0$ everywhere. The symmetric components are increased by a factor of 5 in the lowest four layers to provide enhanced tropospheric mixing (thus avoiding a buildup of chlorofluoromethanes near the ground where the diabatic circulation is a very poor approximation) and tapered down to the above values over the intervening five layers. These values are large enough to provide damping of waves produced by irregularities in the velocity fields but small in the sense that in the stratosphere the advective terms in the flux divergence equation (equation (3)) are generally larger than the diffusive terms. The values of $K_{y y}$ and $K_{z z}$ are factors of $\sim 20$ and $\sim 2$ larger, respectively, than the numerical diffusion obtained in a square wave test for this grid spacing and time step. These values are an order of magnitude or more below the stratospheric diffusion coefficients used in most other models [Whitten et al., 1977; Vupputuri, 1978; Miller et al., 1981] and quite close to the values recently derived by Kida [1983].

In order to evaluate the use of a given transport parameterization in a model there must be some well-defined standard or figure of merit with which the results can be compared. While the eventual goal in most photochemical models is a self-consistent calculation of all active species, this is not necessarily the most illuminating approach to a test of the transport treatment. Instead, we have fixed ozone (the primary photochemical absorber in the near ultraviolet) at monthly intervals (based on Nimbus 7 BUV data from McPeters et al. [1983]) and injected tracers at the ground for which stratospheric photolysis is the predominant or sole destruction process. We specify a constant mixing ratio of 300 ppbv for $\mathrm{N}_{2} \mathrm{O}$ at the ground. The chlorofluoromethanes F-11 and F-12 are specified as time-dependent and latitude-dependent fluxes according to historical release rates from Bauer [1979] for 1960 through 1974 and from WMO 81 for 1975 through 1980. The model is run to 1980; the time evolution of F-11 and F-12 is shown in Figure 3. The resulting distributions of the three tracers are compared with atmospheric measurements. One reason for selecting this test is that it has always been difficult to define eddy diffusion coefficients that would fit $\mathrm{N}_{2} \mathrm{O}, \mathrm{F}-11$, and F-12 simultaneously [see, for example, Hunten, 1983; Miller et al., 1981]. As will be seen, this parameterization does an almost equally good job for all three.

\section{Results AND Discussion}

Figure 4 shows the equatorial altitude profile for $\mathrm{N}_{2} \mathrm{O}$ obtained from measurements (WMO 81), Miller et al. [1981], Garcia and Solomon [1983], and this study. While the model results are nearly identical below $30 \mathrm{~km}$, they diverge in the upper stratosphere, where the more diffusive transport treatments produce a larger upward flux. A similar effect appears for F-12, as shown in Figure 5. Preliminary analysis of this model, using the previously accepted $\mathrm{O}_{2}$ cross sections of Allen and Frederick [1982], indicates that the differences between this experiment and the Miller et al. results are more probably due to the difference in transport treatment than to the differences in cross sections [Jackman and Guthrie, 1983].
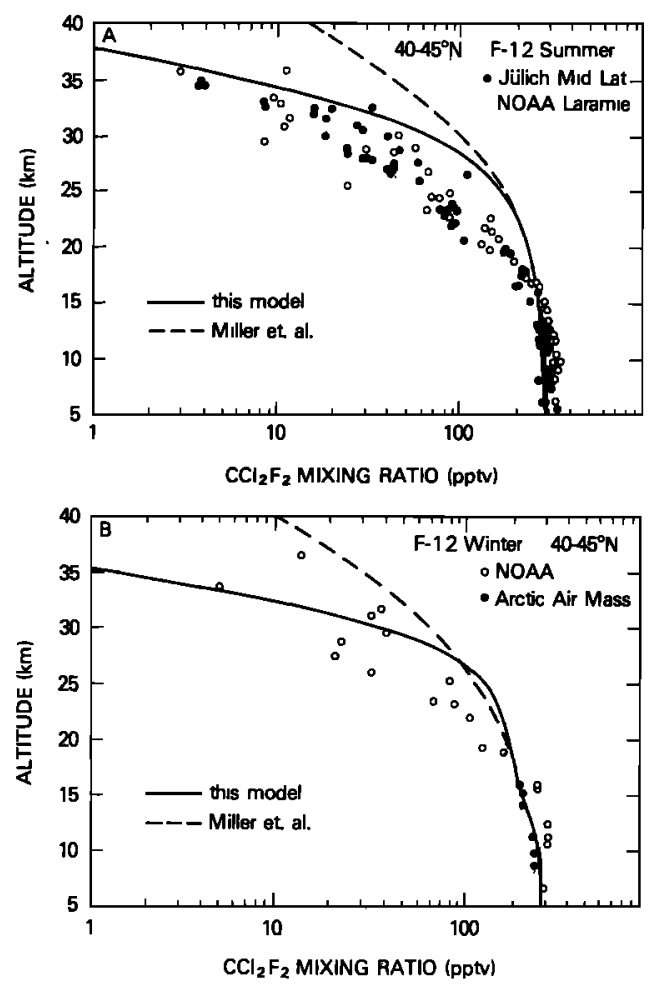

Fig. 8. Computed mid-latitude F-12 profiles vs. measurements for (a) summer, (b) winter. 
The profile for equatorial F-11 (Figure 6) clearly fits the measurements less well, indicating that for this species, even with the revised $\mathrm{O}_{2}$ cross sections, there is possibly still a problem with the photolysis rate. It is, of course, possible to specify other combinations of winds and eddy diffusion coefficients that will produce profiles in good agreement with measurements. Recent work by Gidel et al. [1983] using large eddy diffusion coeflicients and extremely small vertical winds in the lower stratosphere illustrates this. The point here is that the diabatic circulation model, with very little diffusion, does about as well in simulating tracer profiles as tuned eddy diffusion parameterizations, but with a simple physical mechanism as its basis. Whether this simple treatment is adequate for more complex problems remains to be seen.

At mid-latitudes the fit for all three tracers is substantially poorer (Figures $7,8,9$ ) with a consistent overestimate of concentrations in the lower stratosphere. We consider this to be most probably due to the limitations of the circulation, as discussed below.

Several characteristic features of the diabatic circulation are evident in Figure 10, which shows seasonal contour plots of mixing ratio for $\mathrm{N}_{2}$ O. Starting at about $200 \mathrm{mbar}$, there is a "bubble" which represents the effect of upward flowing tropical air (refer to Figure 2). As the upward flow slows and turns poleward, this structure develops anvils that produce larger mixing ratios at mid-latitudes in the lower stratosphere than those found in the real atmosphere. This results in the "shoulder" between 20 and $30 \mathrm{~km}$ on the profiles in Figures 7-9. Similar structures have been reported by Ko et al. [1983] (for a model with the lower boundary at the tropopause) and are suggested by the data of Krey et al. [1977]. However, as the profiles indicate, any such structure in the real atmosphere must be confined to lower latitudes. The shoulder in the midlatitude profiles occurs where the flow (again refer to Figure 2) is primarily meridional, that is, high mixing ratio air is flowing upward in the tropics and then poleward in the mid-latitudes between 50 and 10 mbar. This flow does not begin to descend until it reaches $\sim \pm 50^{\circ}$ in latitude. The latitudinal extent of the lower stratospheric circulation cell and the position of the descending portion are determined by the location of the change from net heating to net cooling in the atmosphere. Since the heating rates in the lower stratosphere are small and depend on somewhat uncertain measurements of water vapor concentrations [Dopplick, 1974, 1979] as well as other trace gas distributions, it is quite possible that the actual transition from net heating to net cooling in the lower stratosphere occurs at lower latitudes than the transition shown in our heating rates. If so the position of the descending side of the cell should be farther equatorward, which would tend to reduce the mismatch in the mid-latitude profiles.

The altitude of the heating rate transition that generates this cell (see Figure $1 a$ ) is between about 100 and 50 mbar, corresponding to the center of the circulation cell. This is well below the region of merging the two heating rate data sets and thus unlikely to be affected by the merging procedure. Doubling or halving the heating rates everywhere produces the expected increase and decrease, respectively, in the wind velocities but does not change the location of the cell center. It is the sign change in the heating rates that determines the latitude of the descent. Comparison with measurements and the presence of the shoulder in our calculated mid-latitude profiles are taken to indicate that the lower stratospheric heating rates used have a heating-to-cooling transition at a more poleward
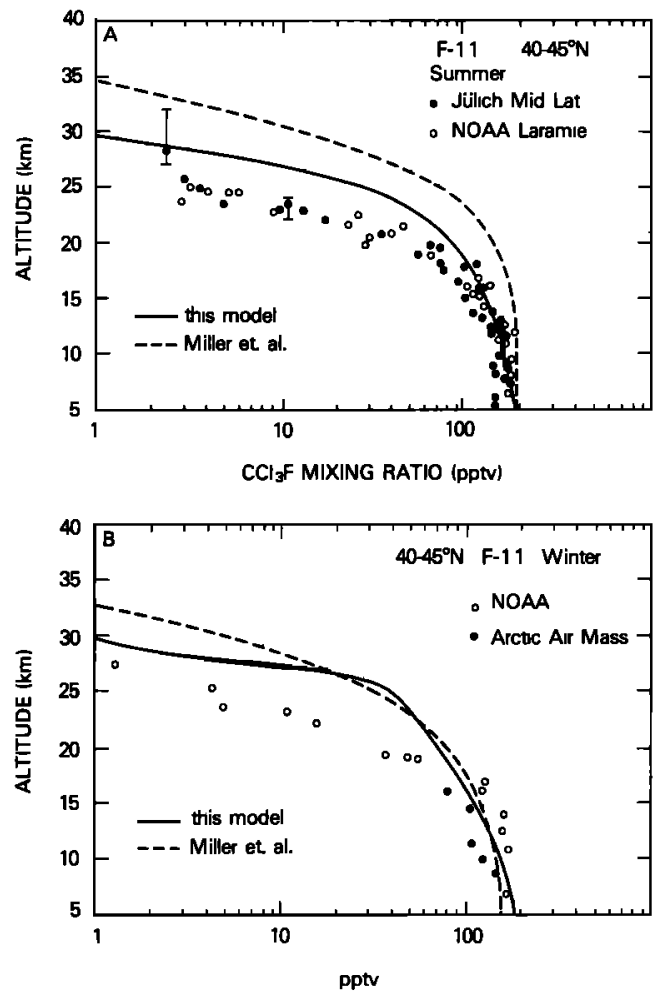

Fig. 9. Computed mid-latitude F-11 profiles vs. measurements for (a) summer, (b) winter.

position than does the actual atmosphere. A similar interpretation was suggested by Garcia and Solomon [1983] on the basis of both upward and downward flowing constituents.

It is, of course, still possible that the mid-latitude mismatch is due to inherent limitations in the applicability of the diabatic circulation or to our use of latitude-invariant eddy diffusion coefficients. However, the mismatch is not substantially reduced in summer, when wave dissipation and transience effects are usually reduced in the real atmosphere and the diabatic approximation is likely to be very good. As for the uniform diffusion, while real atmospheric mixing processes are undoubtedly variable in both time and space, the appropriate distribution for use with a residual mean circulation is still an open question.

In considering the transport characteristics of different models it must be remembered that the values of eddy diffusion coefficients may not be directly comparable. The values chosen for the $K$ 's in a given model will depend on the formulation of that model and the physics being parameterized within the $K$ theory approach. It is incorrect to use $K$ values derived from Eulerian mean winds and wind variances in a formulation based on the residual mean circulation or the diabatic approximation thereto. Within the diabatic circulation approximation, eddy diffusion is presumed to represent only irreversible mixing processes, such as turbulent diffusion. Within the Eulerian formulation, the eddy coefficients must also represent systematic motions that are nearly equal in magnitude to those represented by the Eulerian mean winds.

The $K$ values used here, while small compared to those used in most other 2-D models, may not be small compared to those appropriate to the residual mean formulation. Kida [1983], for example, derived values very similar to these in attempting to model trajectories in the lower stratosphere. 

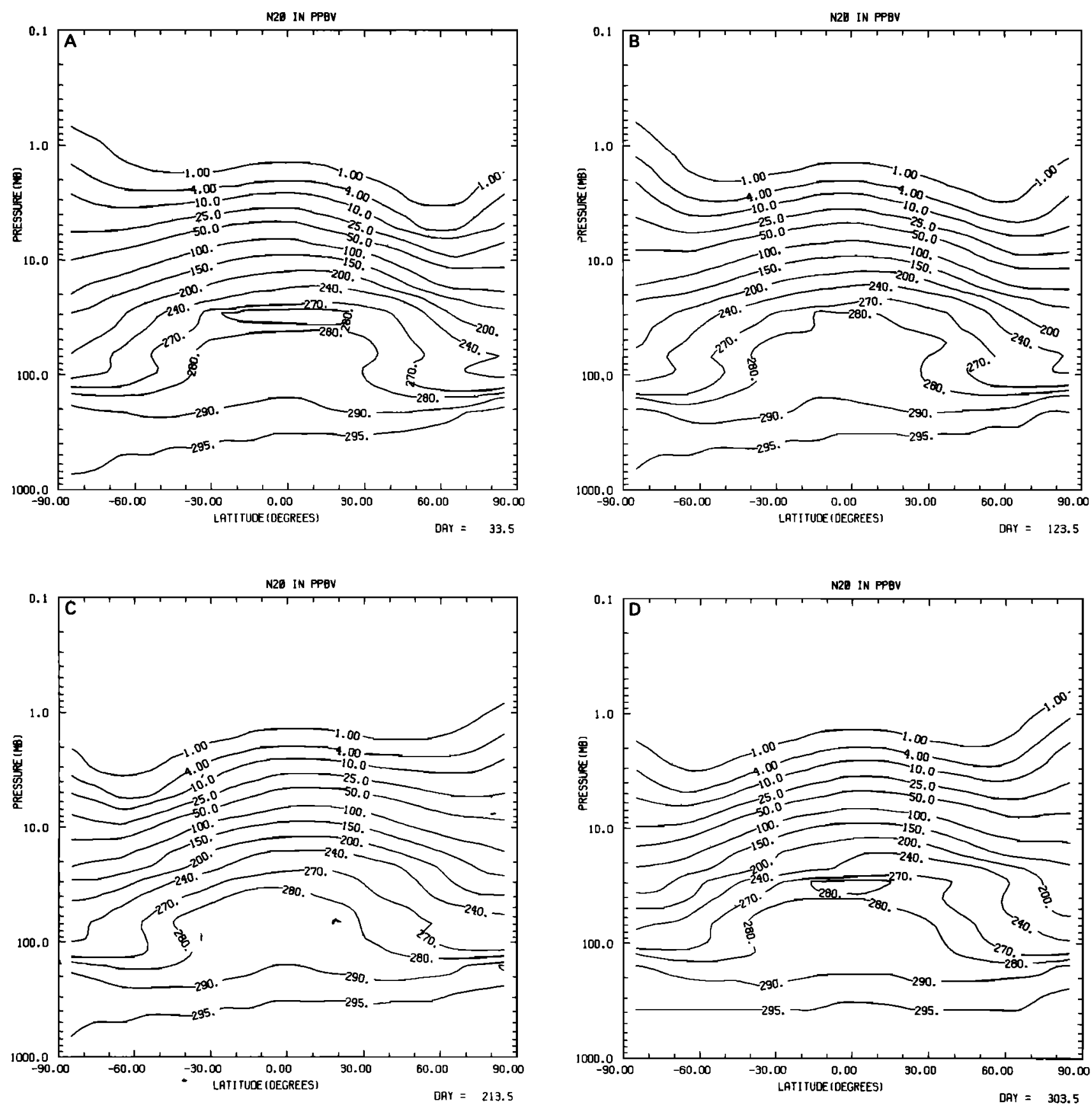

Fig. 10. Height-latitude distributions of $\mathrm{N}_{2} \mathrm{O}$ for (a) winter, (b) spring, (c) summer, (d) fall. The time is 1 month after the relevant equinox or solstice.

They are small in the sense that, for tracer studies, the flux divergence terms resulting from eddy diffusion are much less than those resulting from advection everywhere in the stratosphere, as required for a test of the ability of the diabatic circulation to simulate tracer distributions.

In the real atmosphere the location and intensity of mixing motions will clearly vary with time, and the use of spatially and temporally invariant eddy coefficients in the model stratosphere is not intended to be a good model of actual physical mixing processes. It is rather a fairly severe test of the contention that such variations may be neglected in the diabatic approximation. Experiments based on increasing the value of $K_{z z}$ throughout the stratosphere indicate that an increase of perhaps a factor of 5 is sufficient to reduce the mid-latitude gradients and remove the anvils on the contours. This, however, increases the mixing ratios in the middle and upper stratosphere to values implying a substantially less steep decrease with height than seen in the data. It also violates the diabatic circulation approximation in the lower stratosphere by making the diffusive terms as large as the advective terms. If this is indeed the case, a detailed treatment of the eddy mixing consistent with the residual mean circulation is required.

Another characteristic feature of the contour plots is the transition from the bubble to more nearly flat contours. In this region (above 5 mbar especially) the influence of the direct 

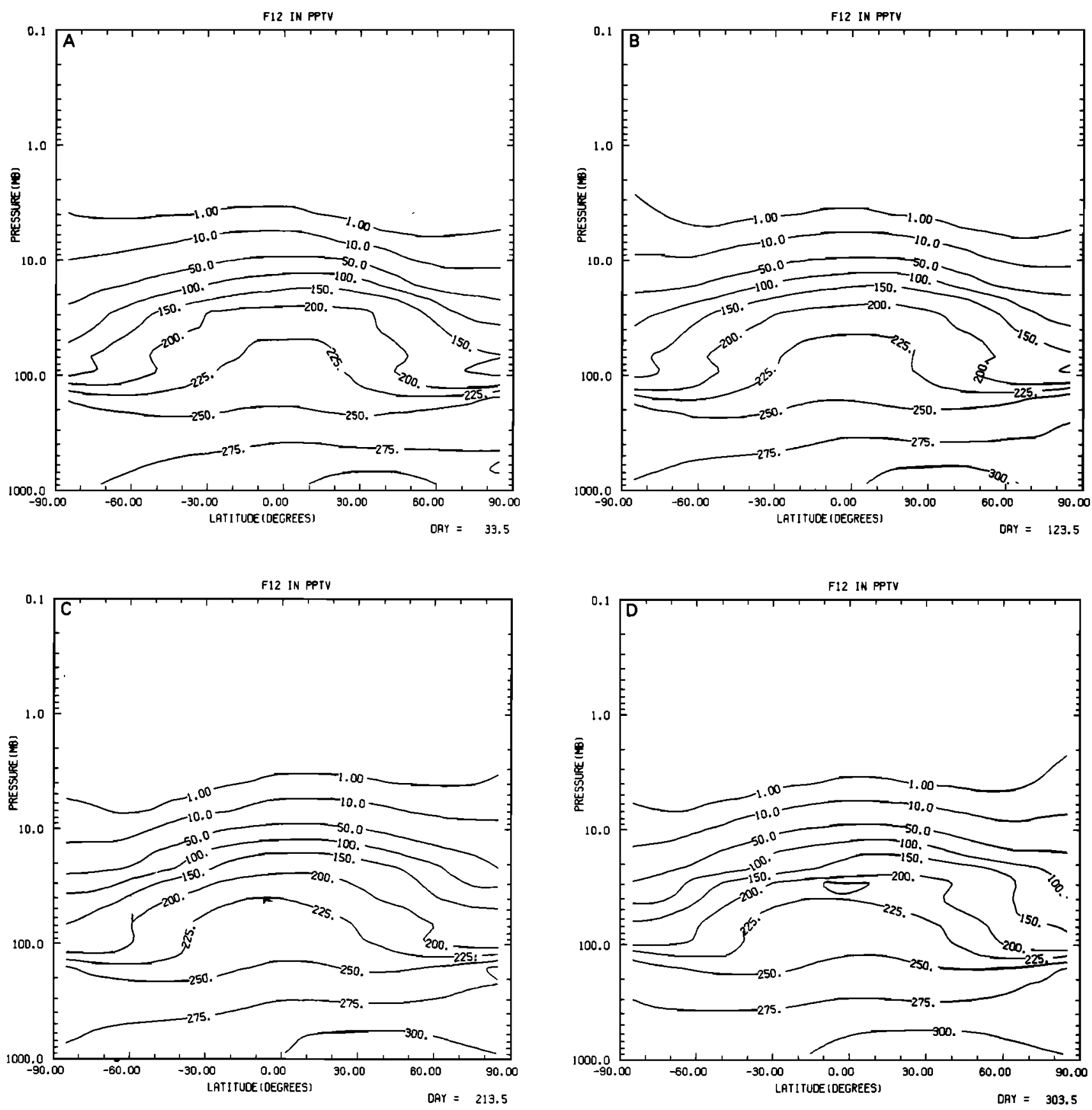

Fig. 11. As in Figure 10, but for F-12.

upper stratospheric transport cell can be seen in the upward displacement of contours toward the summer pole and downward displacement toward the winter pole. There is a suggestion of this in the 3-D $\mathrm{N}_{2} \mathrm{O}$ experiment of Levy et al. [1979], but their figures do not go above $10 \mathrm{mbar}$, where the effect becomes pronounced in this model. It should be possible to test this prediction of summer to winter tilt in the upper stratosphere when satellite-derived $\mathrm{N}_{2} \mathrm{O}$ observations over a full year become available. Preliminary data on $\mathrm{N}_{2} \mathrm{O}$ distributions from the SAMS (Stratospheric and Mesospheric Sounder) experiment [Crutzen and Schmailzl, 1983] indicate that actual atmospheric gradients above $35 \mathrm{~km}$ are not as steep as those obtained here. The stated accuracy of these measurements is $\pm 35 \%$ at $40 \mathrm{~km}$ and $\pm 100 \%$ at $50 \mathrm{~km}$, so that the gradient at high altitudes may in fact be somewhat steeper than indicated; in any case the SAMS measurements show $\mathrm{N}_{2} \mathrm{O}$ falling off more rapidly than in models with large $K_{z}$ values at high altitudes. The SAMS measurements do not show the tilt in concentration contours of $\mathrm{N}_{2} \mathrm{O}$ at high altitudes for solstice conditions, although they do show a similar tilt effect for methane. The difference may be due to latitudinal variations in $\mathrm{CH}_{4}$ loss rates, but the concentration is highest in the summer hemisphere, where one would expect the loss rate to be largest. This discrepancy may be resolved when further studies of SAMS data become available.

Comparing the seasonal variation of $\mathrm{N}_{2} \mathrm{O}$ (Figure 10) to that of F-12 or F-11 (Figures 11 and 12), respectively, we find an interesting effect caused by the latitudinal variation of source strength for the CFM's. Not only does the bubble shift back and forth, the entire distribution rises (that is, a given 

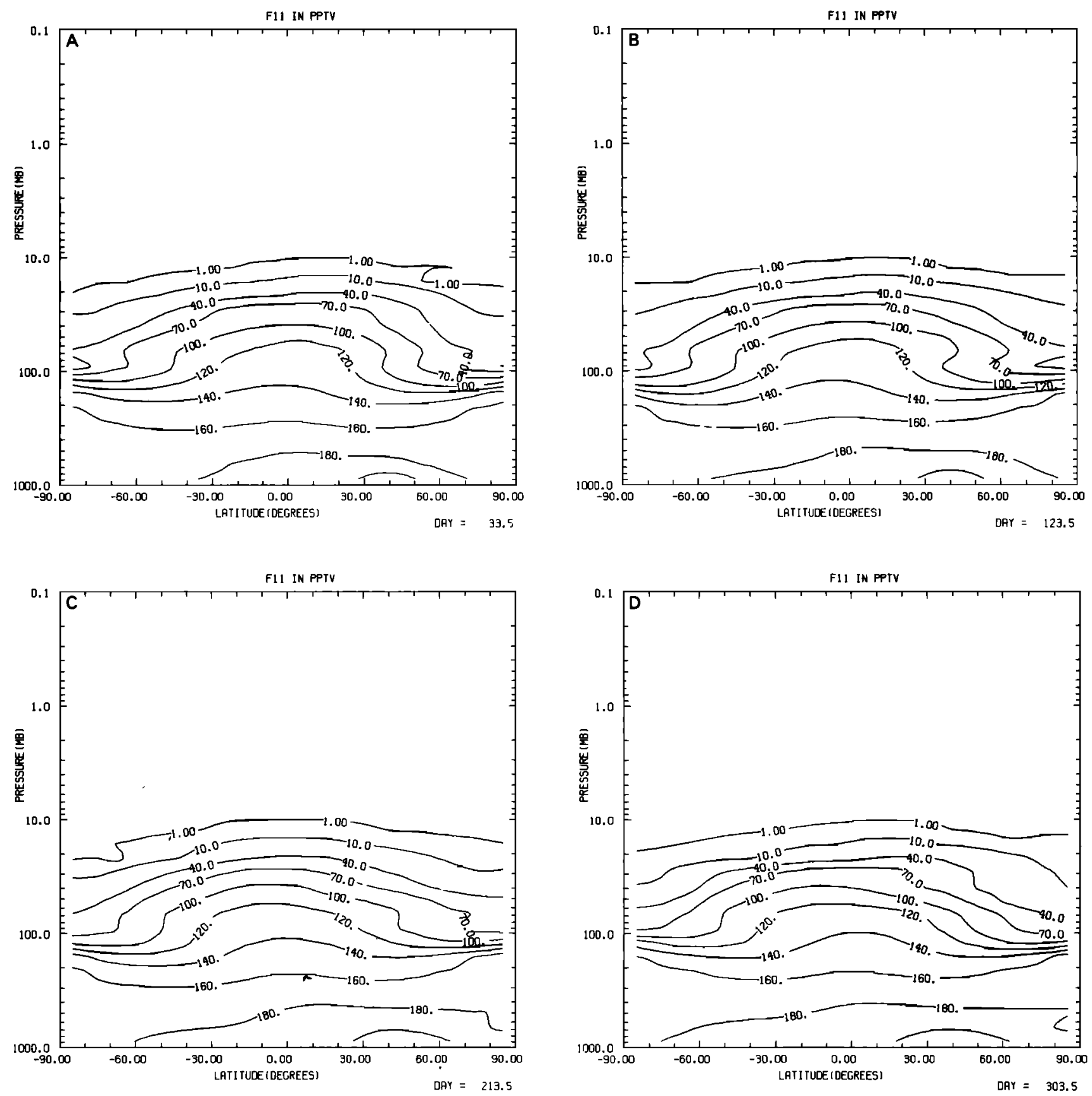

Fig. 12. As in Fig. 10, but for F-11.

contour occurs at a higher altitude) and falls with season. This is an effect of the increased effective flux when the region of rising motion coincides with the greater ground source strength in the northern hemisphere (the northern hemisphere contributes about $90 \%$ of the total flux of CFM's). Since there are indications that a number of source species (e.g., $\mathrm{CH}_{4}$, $\mathrm{CH}_{3} \mathrm{Cl}$ ) are biologically mediated, and thus potentially both spatially and temporally variable, and since the fluxes of anthropogenic source gases are known to be highly concentrated in northern mid-latitudes, there is the possibility of significant enhancement or suppression of effective stratospheric source fluxes, depending on the phase relationship between the ground flux and the vertical transport.

\section{Lifetime Calculation}

In comparing seasonally variable species distributions between models or between a model and measurements it is difficult to characterize the differences in terms of simple largescale influences of the transport treatment. Although we have concentrated on large structures in the distributions, one can also compare models in terms of quantities that integrate the overall effects of the model formulation. One such is the mean lifetime, which for these species is a measure of the overall efliciency of the transport in moving constituents from the ground source to altitudes where they can be rapidly photolyzed. 
For any species a yearly and globally averaged lifetime can be defined as

$$
T_{L}=\frac{\int^{1 \mathrm{yr}} \int_{-90^{\circ}}^{90^{\circ}} c(t, \phi) \sin \phi d \phi d t}{\int^{1 \mathrm{yr}} \int_{0}^{10 \mathrm{p}} \int_{-90^{\circ}}^{90^{\circ}} L_{n} S_{n} \sin \phi d \phi d Z d t}
$$

where $L_{n}$ and $S_{n}$ are as given earlier and $c(t, \phi)$ is the column content $\left(\# \mathrm{~cm}^{-2}\right)$ of the species $n$ at time $t$ and latitude $\phi$. Using this expression for $\mathrm{N}_{2} \mathrm{O}$, we calculate a lifetime of 168 years. This value may be compared with 159 years calculated by Ko and Sze [1982], 175 years calculated by Johnston et al. [1979], and 150 years computed by Levy et al. [1979].

\section{CONCLUSION}

It has now become widely (though not universally) accepted that "... the residual [mean] circulation provides a more rational basis for constructing two-dimensional photochemical models than does the conventional Eulerian approach" [Holton, 1981]. The simplest approximation to the residual mean is the diabatic circulation, which neglects the effects of advective eddy transport and all forms of dissipative mixing, although the actual importance of this mixing and its distribution have not been determined. We have investigated the ability of a model based on the diabatic circulation with a small amount of dissipative mixing everywhere to simulate the atmospheric distribution of the tracers $\mathrm{N}_{2} \mathrm{O}, \mathrm{F}-11$, and $\mathrm{F}-12$. The model profiles are in reasonable agreement with data for the tropics, although as in most other models, F-11 is the worst case. Contrary to other efforts to model these species by using the diabatic or residual mean circulation [Miller et al., 1981; Garcia and Solomon, 1983] our profiles fall off quite sharply with altitude in the middle and upper stratosphere, as suggested by the data, although there is insufficient highaltitude data to make a strong distinction between the fits of the model profiles to the data. We attribute our steeper profiles to the difference in treatment of vertical eddy diffusion, which is more than an order of magnitude smaller in this model (above $20 \mathrm{~km}$ ) than in both Miller et al. and Garcia and Solomon.

The greatest divergence between the model profiles and measurements occurs at mid-latitudes between about 20 and $30 \mathrm{~km}$, where the model is substantially above the data. This is also the region of greatest uncertainty in heating rates. For latitudes poleward of the position of the descending branch of the lower stratospheric circulation cell the profiles between 20 and $30 \mathrm{~km}$ will reflect a downward flow of stratospheric, lowmixing-ratio air. For latitudes equatorward of the transition to descent this altitude range will have mixing ratios characteristic of the upward and poleward flowing tropical air. If the position of this transition is farther poleward in the model than in the real atmosphere, the mid-latitude model profiles in the "incorrect" region will be higher than those in the atmosphere. The model overestimates in the mid-latitude profiles are thus likely to be due not to any inherent failure of the diabatic approximation but simply to an inadequate knowledge of atmospheric heating rates. It should be noted that lower stratospheric heating rates are small and result from a complex interplay of radiative processes involving several molecular species and subject to variations as a result of cloud cover, aerosol load, and possibly other perturbations; they are thus difficult to determine accurately.
Although the diabatic circulation provides reasonably good tracer profiles, it still offers substantial scope for refinement. In particular, a self-consistent set of heating rate measurements throughout the model domain would alleviate many of the problems caused by merging the two sets of measurements used here. It should also be possible to include advective eddy transport and seasonally variable diffusion coefficients if a climatology of eddy motions can be obtained. The difference between advection-dominated transport and diffusiondominated transport is a fundamental difference in the physical nature of the system being modeled. It is simply not possible to model flows that preserve mixing ratio gradients by using an eddy-diffusion-dominated transport formulation. While mixing processes are certainly important in a zonally averaged atmospheric model, this study demonstrates that it is possible to obtain reasonably good simulations of atmospheric tracer profiles without depending on tuned, eddy diffusion coefficients. The ability to characterize the role of transport in terms of direct advective flows may simplify the problem of understanding the photochemistry of the transition region of the stratosphere, where the chemical and dynamical time scales coincide.

\section{APPENDIX A}

For a given molecular species the continuity equation (1) may be dominated by advection, diffusion, or photochemistry at various times of the year and in different parts of the model grid. Furthermore, at any given time and location the set of continuity equations to be solved simultaneously may be quite stiff, i.e, the range of time scales involved may be very broad. The numerical scheme to be used must thus be quite flexible.

We have used an alternating direction explicit approach in which the time differencing is forward, but the time centering of the spatial finite differences varies with the direction of integration. For odd time steps we proceed from "southwest" to "northeast," and the computational molecule for interior grid points looks like:

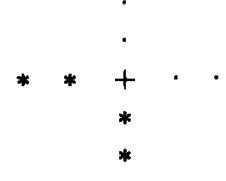

The model is solved at the point marked " + ' with spatial derivatives expressed in terms of the (just computed) $n+1$ th time step at the points marked " $*$ " and the $n$th time step at the points marked ".". For even time steps we sweep in the opposite direction and the molecule looks like:

\section{All model results are evaluated at even time steps.}

The finite difference approximation for the spatial derivatives is fourth order in both coordinates. For interior points the standard expressions for centered differences are used, i.e., 




Fig. Al. Arrangement of grid points near a corner showing boundary (B), semiboundary (SB), and interior (I) types in both dimensions.

for any function $S(y, z)$

$$
\begin{aligned}
\left.\Delta z^{2} \frac{\partial^{2} S}{\partial z^{2}}\right|_{j, k}=\frac{4}{3}\left(S_{j, k-1}-2 S_{J, k}+\right. & \left.S_{j, k+1}\right) \\
& -\frac{1}{12}\left(S_{j, k-2}-2 S_{j, k}+S_{J, k+2}\right)
\end{aligned}
$$$$
\left.\Delta z \frac{\partial S}{\partial z}\right|_{j, k}=\frac{2}{3}\left(S_{j, k+1}-S_{j, k-1}\right)-\frac{1}{12}\left(S_{j, k+2}-S_{j, k-2}\right)
$$

However, as one approaches the grid boundaries the centered form can no longer be used.

There are two classes of grid points for which special finite difference forms must be developed, as shown in Figure Al. The type indications B (boundary), SB (semiboundary), and I (interior) indicate the finite difference form used in the $(y, z)$ coordinate derivatives. Since the points are box centered, the difference expressions at B and SB points involve boundary conditions that are specified at locations a half step outside the grid (marked $x$ in the figure).

The semiboundary expressions are obtained by writing the value of the function at the next two interior points, the "boundary" grid point, and the actual boundary in terms of a fourth-order Taylor series expansion around the semiboundary grid point (see Lapidus and Pinder [1982] or most other books on finite difference techniques for an explanation of the procedure). The finite difference forms are, at a lower semiboundary in a given coordinate $x$ (the other subscript has been suppressed but remains constant),

$$
\begin{gathered}
\left.\frac{1}{2}(\Delta x)^{2} \frac{\partial^{2} S}{\partial x^{2}}\right|_{i}=-\frac{1}{21} S_{t+2}+\frac{7}{10} S_{i+1}-\frac{4}{3} S_{i}+\frac{5}{6} S_{i-1}-\frac{16}{105} S_{B} \\
\left.\Delta x \frac{\partial S}{\partial x}\right|_{i}=-\frac{1}{14} S_{i+2}+\frac{3}{5} S_{i+1}+\frac{1}{6} S_{i}-S_{i-1}+\frac{32}{105} S_{B}
\end{gathered}
$$

at an upper semiboundary,

$$
\begin{aligned}
\left.\frac{1}{2}(\Delta x)^{2} \frac{\partial^{2} S}{\partial x^{2}}\right|_{i} & =-\frac{1}{21} S_{i-2}+\frac{7}{10} S_{t-1}-\frac{4}{3} S_{i}+\frac{5}{6} S_{i+1}-\frac{16}{105} S_{B} \\
\left.\Delta x \frac{\partial S}{\partial x}\right|_{i} & =\frac{1}{14} S_{i-2}-\frac{3}{5} S_{t-1}-\frac{1}{6} S_{t}+S_{i+1}-\frac{32}{105} S_{B}
\end{aligned}
$$

where $S_{B}$ denotes the value of the function on the actual boundary. Similarly, for "boundary" (B) points: at a lower boundary grid point,

$$
\begin{gathered}
\left.\frac{1}{2}(\Delta x)^{2} \frac{\partial^{2} S}{\partial x^{2}}\right|_{i}=\frac{1}{42} S_{i+3}-\frac{1}{5} S_{i+2}+\frac{7}{6} S_{i+1}-\frac{8}{3} S_{i}+\frac{176}{105} S_{B} \\
\left.\Delta x \frac{\partial S}{\partial x}\right|_{i}=\frac{1}{21} S_{i+3}-\frac{3}{10} S_{i+2}+S_{i+1}+\frac{1}{6} S_{i}-\frac{32}{35} S_{B}
\end{gathered}
$$

at an upper boundary grid point

$$
\begin{gathered}
\left.\frac{1}{2}(\Delta x)^{2} \frac{\partial^{2} S}{\partial x^{2}}\right|_{i}=\frac{1}{42} S_{i-3}-\frac{1}{5} S_{i-2}+\frac{7}{6} S_{t-1}-\frac{8}{3} S_{i}+\frac{176}{105} S_{B} \\
\left.\Delta x \frac{\partial S}{\partial x}\right|_{i}=-\frac{1}{21} S_{i-3}+\frac{3}{10} S_{i-2}-S_{i-1}-\frac{1}{6} S_{i}+\frac{32}{35} S_{B}
\end{gathered}
$$

Similar expressions may be developed for the cross derivative if required.

The species continuity equations are solved simultaneously at the current grid point by using Newton-Raphson iteration. This technique provides good accuracy and reasonable comchemical production and loss terms become large. Overall, the model is quite stable for realistic values of the winds and photochemical terms. With constant-mixing ratio lowerboundary conditions and "reasonable" (e.g., approximate annual average) initial species distributions, the model typically converges to a repeating annual cycle in 3 to 7 years of model time, depending on the heating rates and ozone distribution being used.

The error characteristics of this scheme are similar to those of other fourth-order schemes [see Mahlman and Sinclair, 1977] in that it is not quite quadratic conserving and is slightly dispersive. The time-differencing scheme is less diffusive than the leapfrog approach, based on a square wave test. The approach is referred to as "angled derivative" [Roberts and Weiss, 1966] and has also been investigated by Piacsek and Williams [1970]. Even in the extreme square-wave test, the numerical diffusion is less than half the minimum explicit diffusion in the vertical dimension and less than $5 \%$ of that in the meridional dimension. For smoother distributions the dissipation caused by numerical diffusion is less.

$$
\begin{aligned}
& \mathrm{O}_{2}+h v \rightarrow \mathrm{O}+\mathrm{O} \\
& \mathrm{O}_{3}+h v \rightarrow \mathrm{O}_{2}+\mathrm{O} \\
& \mathrm{O}_{3}+h v \rightarrow \mathrm{O}_{2}+\mathrm{O}\left({ }^{1} \mathrm{D}\right) \\
& \mathrm{N}_{2} \mathrm{O}+h v \rightarrow \mathrm{N}_{2}+\mathrm{O}\left({ }^{1} \mathrm{D}\right) \\
& \mathrm{CFCl}_{3}+h v \rightarrow \text { products } \\
& \mathrm{CF}_{2} \mathrm{Cl}_{2}+h v \rightarrow \text { products } \\
& \mathrm{N}_{2} \mathrm{O}+\mathrm{O}\left({ }^{1} \mathrm{D}\right) \rightarrow \mathrm{N}_{2}+\mathrm{O}_{2} \\
& \mathrm{~N}_{2} \mathrm{O}+\mathrm{O}\left({ }^{1} \mathrm{D}\right) \rightarrow \mathrm{NO}+\mathrm{NO} \\
& \mathrm{CFCl}_{3}+\mathrm{O}\left({ }^{1} \mathrm{D}\right) \rightarrow \text { products } \\
& \mathrm{CF}_{2} \mathrm{Cl}_{2}+\mathrm{O}\left({ }^{1} \mathrm{D}\right) \rightarrow \text { products } \\
& \mathrm{O}\left({ }^{1} \mathrm{D}\right)+\mathrm{N}_{2} \rightarrow \mathrm{O}+\mathrm{N}_{2} \\
& \mathrm{O}\left({ }^{1} \mathrm{D}\right)+\mathrm{O}_{2} \rightarrow \mathrm{O}+\mathrm{O}_{2} \\
& \mathrm{O}\left({ }^{1} \mathrm{D}\right)+\mathrm{N}_{2}+\mathrm{M} \rightarrow \mathrm{N}_{2} \mathrm{O}+\mathrm{M} \\
& \mathrm{O}\left({ }^{1} \mathrm{D}\right)+\mathrm{O}_{3} \rightarrow \mathrm{O}_{2}+\mathrm{O}_{2} \\
& \mathrm{O}\left({ }^{1} \mathrm{D}\right)+\mathrm{O}_{3} \rightarrow \mathrm{O}_{2}+\mathrm{O}+\mathrm{O}
\end{aligned}
$$


Acknowledgment. The authors gratefully acknowledge useful discussions with R. B. Rood, H-R. Schneider, and R. S. Stolarski.

\section{REFERENCES}

Allen, M., and J. E. Frederick, Effective photodissociation cross sections for molecular oxygen and nitric oxide in the SchumannRunge bands, J. Atmos. Sci., 39, 2066-2075, 1982.

Bauer, E., A catalog of perturbing infiuences on stratospheric ozone, 1955-1975, J. Geophys. Res., 84, 6929-6940, 1979.

Brasseur, G., A. De Rudder, and P. C. Simon, Implication for stratospheric composition of a reduced absorption cross section in the Herzberg continuum of molecular oxygen, Geophys. Res. Lett., 10, $20-23,1983$.

Crutzen, P. J., A two-dimensional photochemical model of the atmosphere below $55 \mathrm{~km}$ : Estimates of natural and man-caused ozone perturbations due to $\mathrm{NO}_{x}$, Proceedings of the Fourth Conference on CIAP, Rep. DOT-TSC-OST-75-38, pp. 264-279, U.S. Dep. Transp., Wash., D. C., 1975.

Crutzen, P. J., and U. Schmailzl, Chemical budgets of the stratosphere, Planet. Space Sci., 31, 1009-1032, 1983.

Cunnold, D., F. Alyea, N. Philip, and R. Prinn, A three-dimensional dynamical-chemical model of atmospheric ozone, J. Atmos. Sci., 32, 170-194, 1975.

Danielson, E. F., An objective method for determining the generalized transport tensor for two-dimensional eulerian models, J. Atmos. Sci., 38, 1319-1339, 1981.

Dopplick, T. G., The heat budget, in The General Circulation of the Tropical Atmosphere and Interactions With Extratropical Latitudes, vol. 2, chap. 7, edited by R. E. Newell, J. W. Kidson, D. G. Vincent, and C. J. Boer, The MIT Press, Cambridge, Mass., 1974.

Dopplick, T. G., Radiative heating of the global atmosphere: Corrigendum, J. Atmos. Sci., 36, 1812-1817, 1979.

Dunkerton, T., On the mean meridional mass motions of the stratosphere and mesosphere, J. Atmos. Sci., 35, 2325-2333, 1978.

Froidevaux, I., and Y. L. Yung, Radiation and chemistry in the stratosphere: Sensitivity to $\mathrm{O}_{2}$ absorption cross sections in the Herzberg continuum, Geophys. Res. Lett., 9, 854-857, 1982.

Garcia, R. R., and S. Solomon, A numerical model of the zonally averaged dynamical and chemical structure of the middle atmosphere, J. Geophys. Res., 88, 1379-1400, 1983.

Gidel, L. T., P. J. Crutzen, and J. Fishman, A two-dimensional photochemical model of the atmosphere, 1 , Chlorocarbon emissions and their effect on stratospheric ozone, J. Geophys. Res., 88, 6622-6640, 1983.

Harwood, R. S., and J. A. Pyle, A two-dimensional mean circulation model for the atmosphere below $80 \mathrm{~km}, Q$. J. R. Meteorol. Soc., $101,723-747,1975$.

Harwood, R. S., and J. A. Pyle, Studies of the ozone budget using a zonal mean circulation model and linearized photochemistry, $Q$. $J$. R. Meteorol. Soc., 103, 319-343, 1977.

Hasson, V., and R. W. Nicholls, Absolute spectral absorption measurements on molecular oxygen from $2640-1920 \AA, 2$, Continuum measurements 2430-1920 Å, J. Phys. B: At. Molec. Phys., 4, 1789-1797, 1971.

Herman, J. R., The response of stratospheric constitutents for a solar eclipse, sunrise, and sunset, J. Geophys. Res., 84, 3701-3710, 1979.

Herman, J. R., and J. E. Mentall, $\mathrm{O}_{2}$ absorption cross sections (187$225 \mathrm{~nm}$ ) from stratospheric solar flux measurements, $J$. Geophys. Res., 87, 8967-8975, 1982.

Holton, J. R., An advective model for two-dimensional transport of stratospheric trace species, J. Geophys. Res., 86, 11,989-11,994, 1981.

Holten, J. R., and W. M. Wehrbein, A numerical model of the zonal mean circulation of the middle atmosphere, Pure Appl. Geophys., 118, 284-306, 1980.

Hunten, D. M., A second-order effect of stratospheric vertical motions, Geophys. Res. Lett., 10, 333-336, 1983.

Jackman, C. H., and P. D. Guthne, Two-dimensional chemistry of the trace gases $\mathrm{N}_{2} \mathrm{O}, \mathrm{CFCl}_{3}, \mathrm{CF}_{2} \mathrm{Cl}_{2}$ : Effects of a reduced absorption cross-section in the Herzberg continuum of molecular oxygen, paper presented at Spring Meeting, AGU, Baltimore, Md., 1983.

Johnston, H. S., O. Serange, and J. Podolske, Instantaneous global nitrous oxide photochemical rate, J. Geophys. Res., 84, 5077-5082, 1979.

Kida, H., General circulation of air parcels and transport in the stratosphere and troposphere derived from CCM, 1, Mean mass flow in the lower stratosphere, J. Meteorol. Soc. Jpn., 61, 171-186, 1983.

Ko, M. K. W., and N. D. Sze, A 2-D model calculation of atmospheric lifetime for $\mathrm{N}_{2} \mathrm{O}, \mathrm{CFC}-11$ and CFC-12, Nature, 297, 317-319, 1982.

Ko, M. K. W., N. D. Sze, K. K. Tung, and D. Hutchison, Numerical simulation of trace gas distribution using an advective zonal-mean model, paper presented at Spring Meeting, AGU, Baltimore, Md., 1983.

Krey, P. W., R. J. Lagomarsino, and L. E. Toonkel, Gaseous halogens in the atmosphere in 1975, J. Geophys. Res., 82, 1753-1766, 1977.

Krueger, A. J., Sighting of El Chichon sulfur dioxide clouds with the Nimbus 7 total ozone mapping spectrometer, Science, 220, 1377$1379,1983$.

Lapidus, L., and G. F. Pinder, Numerical Solution of Partial Differential Equations in Science and Engineering, John Wiley, New York, 1982.

Levy, H., J. N. Mahlman, and W. J. Moxim, A preliminary report on the numerical simulation of the three-dimensional structure and variability of atmospheric $\mathrm{N}_{2} \mathrm{O}$, Geophys. Res. Lett., 6, 155-158, 1979.

Logan, J. A., M. J. Prather, S. C. Wofsy, and M. B. McElroy, Tropospheric chemistry: A global perspective, J. Geophys. Res., 96, 7210$7254,1981$.

Mahlman, J. D., Some fundamental limitations of simplified transport models as implied by results from a three-dimensional general circulation/tracer model, Proceedings of the Fourth Conferene Climatic Impact Assessment Program, Rep. DOT-TSC-OST-75-38, edited by T. M. Hard and A. J. Broderick, pp. 132-146, U.S. Dep. Transp., Wash., D. C., 1975.

Mahlman, J. D., and R. W. Sinclair, Tests of various numerical algorithms applied to a simple trace constituent air transport problem, in Fate of Pollutants in the Air and Water Environments, Part 1, vol. 8., edited by Irwin H. Suffet, John Wiley, New York, 1977.

McCartney, E. J., Optics of the Atmosphere, John Wiley, New York, 1976.

McPeters, R. D., D. F. Heath and P. K. Bhartia, Average ozone profiles from SBUV 1979, J. Geophys. Res., 89, 5199-5214, 1984.

Miller, C., D. L. Filkin, A. J. Owens, J. M. Steed, and J. P. Jesson, A two-dimensional model of stratospheric chemistry and transport, $J$. Geophys. Res., 86, 12,039-12,065, 1981.

Mount, G. H., and G. J. Rottman, The solar spectral irradiance 1200$3184 \AA$ near solar maximum: July $15,1980, J$. Geophys. Res., 86, 9193-9198, 1981.

Murgatroyd, R. J., The structure and dynamics of the stratosphere, in The Global Circulation of the Atmosphere, edited by C. A. Corby, pp. 159-195, Royal Meteorology Society, London, 1969.

Murgatroyd, R. J., and F. Singleton, Possible meridional circulation in the stratosphere and mesosphere, Q.J.R. Meteorol. Soc., 87, $125-135,1961$.

Newell, R. E., J. W. Kidson, D. G. Vincent, and G. J. Boer, The General Circulation of the Tropical Atmosphere, vol. 2, chap. 7, MIT Press, Cambridge, Mass., 1974.

Piacsek, S. A., and G. P. Williams, Conservation properties of convection difference schemes, J. Comput. Phys., 6, 392-405, 1970.

Pyle, J. A., and C. F. Rogers, A modified diabatic circulation model for stratospheric tracer transport, Nature, 287, 711-714, 1980.

Reed, R. J., and K. E. German, A contribution to the problem of stratospheric diffusion by large-scale mixing, Mon. Weather Rev., 93, 313-321, 1965.

Roberts, K. V., and N. O. Weiss, Convective difference schemes, Math. Comput., 20, 272-299, 1966.

Robock, A., and M. Matson, Circumglobal transport of the El Chichon volcanic dust cloud, Science, 22J, 195-197, 1983.

Rundel, R. D., Determination of diurnal average photodissociation rates, J. Atmos. Sci., 34, 639-641, 1977.

Schoeberl, M. R., and D. F. Strobel, Numerical simulation of sudden stratospheric warmings, J. Atmos. Sci., 37, 214-236, 1980.

Vupputuri, R. K. R., The structure of the natural stratosphere and the impact of chlorofluoromethanes on the ozone layer investigated in a 2-D time dependent model, Pure Appl. Geophys., 117, 448-485, 1978.

Whitten, R. C., W. J. Borucki, V. R. Watson, T. Schimazaki, H. T. Woodward, C. A. Riegel, L. A. Capone, and T. Becker, The NASA Ames Research Center one- and two-dimensional stratospheric models, 2, The two-dimensional model, NASA Tech. Pap. 1003, 1977. 
Widhopf, G. F., A two-dimensional photochemical model of the stratosphere, including initial results of inert tracer studies, Proceedings of the Fourth Conference on CIAP, Rep. DOT-TSC-OST75-38, pp. 316-331, U.S. Dep. Transp., Washington, D. C., 1975.

World Meteorological Organization, The Stratosphere 1981: Theory and Measurements, Rep. NI. 11, Ozone Res. Monit. Proj., Geneva, 1981.
P. D. Guthrie, C. H. Jackman, J. R Herman, and C. T. McQuillan, NASA Goddard Space Flight Center, Atmospheric Chemistry Branch, Code 964, Greenbelt, MD 20771.

(Received September 21, 1983;

revised April 23, 1984; accepted May 8, 1984.) 